doi https://doi.org/10.31977/grirfi.v2li3.2339

Recebido: 23/04/2021 | Aprovado: 29/07/2021

Received: 04/23/2021 | Approved: 07/29/2021

\title{
O TRABALHO PEDAGÓgICO COM A FILOSOFIA NA ESCOLA
}

\author{
Junot Cornélio Matos ${ }^{1}$ \\ Universidade Federal de Pernambuco (UFPE) \\ D https://orcid.org/0000-0002-0669-2066 \\ E-mail: junotcmatos@gmail.com
}

\section{RESUMO:}

$\mathrm{O}$ artigo discute a presença da Filosofia como componente curricular na Escola. Seu objetivo é formular elementos que ensejem a discussão sobre a possibilidade de organização do trabalho pedagógico mediadores de ensino e aprendizagem. Para tanto, faz-se uma breve reflexão sobre a escola, o trabalho docente - notadamente naquilo que se refere à relação professor/aluno.

PALAVRAS-CHAVE: Escola; Ensino de Filosofia; Trabalho Docente; Ensino e Aprendizagem em Filosofia.

\section{THE PEDAGOGICAL WORKS IN CONNECTION TO PHILOSOPHY IN THE SCHOOL}

\begin{abstract}
:
The article discusses the presence of Philosophy as a curricular component in the School. Its objective is to formulate elements that give rise to the discussion on the possibility of organizing pedagogical work, mediators of teaching and learning. For this, a brief reflection is made about the school, the teaching work, notably in what concerns the teacher / student relationship.
\end{abstract}

KEYWORDS: School; Philosophy teaching; Teaching Work; Teaching and Learning in Philosophy.

\footnotetext{
${ }^{1}$ Doutor(a) em Educação pela Universidade de Campinas (UNICAMP), Campinas - SP, Brasil. Professor(a) da Universidade Federal de Pernambuco (UFPE), Recife - PE, Brasil.

MATOS, Junot Cornélio. O trabalho pedagógico com a filosofia na escola. Griot : Revista de Filosofia, Amargosa - BA, v.21 n.3, p.189-196, outubro, 2021.
} 
Ela [a Filosofia] não é nacional, mas internacional. Ela quer ultrapassar toda cultura particular, toda tradição. Seu verdadeiro destino não é a sala de conferência, mas a rua, a praça pública, o mundo inteiro [...] A Filosofia se dá para todo pensamento; ela se dá para o príncipe e para o escravo. (BADIOU, 1994, p. 38)

A perspectiva de pensar possibilidades de reflexão sobre o ensinar e aprender filosofia faznos deparar na complexa tarefa de pensar, ainda que rapidamente, sobre nossas convicções em torno do que vem a ser a filosofia. Dialogo com Ferreira Junior (2011; p. 338) quando registra que "na realidade, a Filosofia não consegue sequer alcançar o mínimo consenso sobre sua própria definição, seu sentido e sua finalidade". Somos, então, tomados por inúmeras questões que costumam nos visitar cada vez que colocamos a temática em questão: Que filosofia? Com quem? Para quem? Para quê? Que ensino2? Que aprendizagem? Tais indagações levaram-me a reviver, assim, minhas especulações do tempo juvenil de uma amizade a um não-saber, a um amor que somente é eterno porque tecido na angústia, no espanto, na curiosidade, na incerteza do tempo que se faz permanentemente, hoje. Um amor que assim se diz porque não sabe, de si, muito dizer. Pois, afinal! o que é o amor? Haverá um conceito capaz de quebrar seu teimoso mover-se? Existirá realmente o amor enquanto coisa singular? Se não existe não é... Se é, somente se desvela no viver. Além disso, posso propor a alguém que ame minha amada? $\mathrm{E}$ a ame da mesma forma e intensidade que eu? Se não, então porque tentar ensinar filosofia? Se sim, então porque essa imprecisão, essa fluidez sempre que tentamos possuí-la? Problemas! Indagações, muitas, várias, mais perguntas que respostas.

Aprendemos e ensinamos que Filosofia é amor, é amar, é bem querer. É amar o não saber que se faz saber na experiência do construir-se como sendo e se expressa nas linguagens forjadas na convivência. É amor contrário a si mesmo pois não se cansa de especular, de questionar suas crenças, de duvidar de seus achados, de reinventar suas possibilidades. Parece construção no chão da vida, do mundo ao qual atribuímos a categoria de humano. Experiência e linguagem, antes que conceito e consciência. Experiência violentando o puro existir na construção da existência que se lê, se diz consciente. Linguagem parida na incessante e insistente labuta do vir-a-ser de homens e mulheres em sua permanente trajetória de inconclusão e mais querer. Filosofia que não é por amar o que será, ou quem sabe pela teimosia em ser um amor devenir. Não por acaso deixamos Badiou (1994) ter a primeira palavra neste trabalho.

Nosso desejo, entretanto, é delimitar as inúmeras possibilidades reflexivas que nossa temática possibilita e contentando-nos em habitar o chão da escola. É nossa intenção desenvolvermos algumas reflexões sobre o trabalho do(a) professor(a) concernentes ao trabalho docente com a componente curricular filosofia. Elegemos a escola como categoria fundante porque concordamos com Masschelein e Simons $(2014$; p. 11) quando defendem que "a escola pode ser reinventada" e por acreditarmos que cabe à filosofia um papel importante no repensamento da Escola.

\section{A Escola: Uma possibilidade do Trabalho Pedagógico Docente}

Centraremos nossa reflexão na escola, considerando que esta é um dos locus privilegiado, no contexto atual, onde a prática educativa formal se desenvolve de forma rigorosa e sistemática. A premissa que organiza nossa discussão alberga-se na compreensão da Escola como um concreto onde se dão diferenciadas práticas sociais que interiorizam atitudes, formas de conduta e aceitação

\footnotetext{
${ }^{2}$ No caso da Filosofia a situação parece paradoxal. As questões relativas ao Ensino de Filosofia e, mesmo, da Filosofia da Educação, parece não encontrarem boa guarida entre filósofos, em Faculdades e /ou Departamentos de Filosofia; e, algumas vezes, em Faculdades e/ou Departamentos de Educação. No caso da Filosofia da Educação, Severino (1999. P. 277) pondera que "a disciplina é "cultivada" apenas como elemento de ensino, ela não gera nenhum processo investigativo para a área".
}

MATOS, Junot Cornélio. O trabalho pedagógico com a filosofia na escola. Griot : Revista de Filosofia, Amargosa - BA, v.21 n.3, p.189-196, outubro, 2021 . 
das relações sociais imperantes. É, ainda, espaço para onde confluem diferentes possibilidades. É, para nós, o locus no qual o professor desenvolve o seu trabalho pedagógico. Entretanto, hoje ela encontra-se na encruzilhada. Discutamos, brevemente, algumas características mais corriqueiramente apresentadas deste ambiente.

Enguita (1989: 163), defende que a obsessão pela manutenção da ordem é uma das características mais importantes que as escolas têm em comum. Vinculada à questão da ordem está a da competência "técnica" do professor para impor a autoridade e a submissão à mesma. Confundem autoridade com autoritarismo, reduzem os estudantes a meros executores de tarefas, previamente, determinadas, como se a autoridade fosse instrumento para estabelecer a submissão, e, portanto, da negação do outro enquanto ser de possibilidades. Dessa forma, segundo esse autor, parece oportuno manter os jovens num estado de dependência crônica: eles não pensam, não sabem, não querem. Eles apenas "aprendem" e obedecem.

Outra marca do trabalho escolar, no que tange ao universo de suas relações, é a impessoalidade. Parece que não existem, em algumas situações, pessoas concretas. As características individuais e as necessidades pessoais são remetidas ao coletivo "alunado" (para alguns, "clientela") e aos parâmetros que delineiam o perfil deste "alunado". $\mathrm{O}$ aluno transformase em número de matrícula, grau de escolaridade, cor de fardamento, etc..., o que se pede é sua adequação ao retrato coletivo, traçado, ou, na categoria em que foram incluídos; "deverá aceitar ser tratado como exercendo um papel mais ou menos preciso: aluno, aluno da terceira série, aluno de geografia da terceira série, aluno repetente de geografia da terceira série, etc." (ENGUITA, op. cit.: 168).

As relações que se desenvolvem, no interior da escola, são, naturalmente, móveis, como todas as demais. Professores e alunos estão envolvidos, em relações complexas, na sala de aula e que envolvem relações sociais, políticas, epistemológicas do próprio saber que está lá, porque o professor é sempre professor de alguma coisa. O espaço micro da "aula" indica que toda produção, que dela deriva, é produto coletivo, a produção do saber, na sala de aula, resulta do trabalho do professor e do aluno. Entretanto, essa relação de reciprocidade parece ser negada, pela atuação arbitraria do professor, sobre a personalidade do aluno.

O tipo de relacionamento que se estabelece, entre professores e alunos, pode, tanto favorecer um ambiente, saudável e propício, para o trabalho pedagógico, quanto inviabilizá-lo. $\mathrm{O}$ cotidiano do trabalho docente é palco de um trabalho invisível, em que, nem sempre, estão postas as condições mínimas necessárias, para uma convivência, favorável ao crescimento dos seus atores, e, às vezes, até, camuflam situações adversas. Costa e Rodrigues (1999: 23) escrevem que este palco está ocupado por professores, alguns dos quais, "desmotivados, cansados e malhumorados"; e, por estudantes mal-orientados que "não sabem ao certo o que esperar e como se comportar na escola". Entretanto, quem é o professor para o aluno? Quem é o aluno para o professor?

A escola é um espaço institucionalizado que se oferece à formação de gerações dando continuidade aos processos de socialização instalados na base das sociedades. Repousa sobre a mesma uma demanda do Estado que a deseja controlada e determina políticas a serem executadas em seu interior e atenderem a objetivos que podem dar sustentação ao próprio Estado. Assim, é possível discutir que o ensino de Filosofia na Escola não é ensino de qualquer filosofia. Mas, antes, daquela que demanda à dinâmica do próprio capital e à formação de um determinado tipo de "cidadão" que o interessa. 


\section{As relações que se constroem no interior da Escola}

A vida cotidiana, na sua totalidade, é construída na partilha com outros. Não apenas no ambiente escolar, diuturnamente estamos em constante contato com outros homens, na comunicação e na interrogação. Mesmo quando estamos sozinhos, na biblioteca, ou realizando tarefas individuais, por exemplo, os outros estão de algum modo "presentes". Mas a presença maciça do outro acontece, na situação face a face (RABUSKE, 1981: 142). Nestas relações, face a face, muitas coisas podem acontecer, inclusive a apreensão da subjetividade, exteriorizada, do outro mediada pelo o máximo de sinais e expressões. Ocorre que, aí, a subjetividade do eu tornase outro, porque objetivada para o mundo além de sua interioridade. Essa apreensão, de realidades ontológicas e existenciais diferentes, propicia, não somente, o encontro de "eus" diferenciados, pelas características peculiares a cada um, mas, ainda, o encontro consigo mesmo. Pois, defendemos que é mediado pelo universo das nossas relações que nós nos percebemos com um.

Freire (1997: 24) defende que ensinar pressupõe aprender, defende que "a reflexão crítica sobre a prática se torna uma exigência da relação Teoria/Prática sem a qual a teoria pode ir virando blábláblá e a prática, ativismo". O aprendizado docente e a construção de específicos saberes profissionais passam por toda sua trajetória de vida. Não é, por acaso, que nos tornamos professor/professora; e muito menos, que nos direcionamos a este ou àquele campo do conhecimento. A formação inicial oferece instrumentos e deve preparar-nos o caminho, abrindo horizontes, para o exercício pertinente à docência. Mas, é no trabalho pedagógico desenvolvido no chão da escola que, efetivamente, configuramos nosso jeito peculiar de ser e atuar, conferindonos uma identidade, em permanente mutação (MATOS, 1998: 303). Entretanto, "o docente maneja habilmente a valorização ou o desprezo, a atenção ou a indiferença e reforça o comportamento de submissão do aluno pela permanência de seu julgamento" (POSTIC, 19984; $p$. 28). Essa autora escreve que

O professor, porque é próprio das pessoas que optam trabalhar no magistério, está continuamente em situação de relacionamento com alunos; um mesmo grupo de alunos durante o ano; vários grupos de alunos durante o ano; grupos ou grupos de alunos a cada ano que passa; grupos ou grupos de alunos que permanecem de um ano para o outro com ele em outra série/ano. Por esta razão, sem dúvida alguma, o maior desgaste que se vive na atividade docente, relaciona-se diretamente com a questão do relacionamento com os alunos e na variedades desses relacionamentos. Esse desgaste é maior ainda quando esta relação é vivida de forma autoritária, centralizadora. (Idem; p. 36)

O exercício da docência nos parece muito exigente. Precisamos nos manter antenados, com um mundo em que a comunicação real e virtual tornou-se uma realidade para muitos, globalizando a velha aldeia. Os estudantes estão conosco para aprenderem e, também, para nos ensinarem. Não é fácil, porém, possível, aprendermos com seus questionamentos, suas experiências de vida, suas dúvidas, suas buscas, embrenharmo-nos no seu universo lingüístico. Há uma grande generosidade inerente à juventude: eles estarão abertos para nós, à medida que nós estejamos abertos para eles. Quem é professor, não o é, somente, de alguma coisa, mas, de alguém. E, na nossa concepção, com alguém.

Em sentido específico, o estudante é, também, formador do seu professor/professora. Então, esta relação deve ser de cordialidade e partilha. Daqui emana a autoridade do docente, como um serviço a liderança de um processo em que ambos estão aprendendo e ensinando ${ }^{3}$. Quanto mais honesta for a relação, mais enriquecedora será para ambas as partes.

\footnotetext{
${ }_{3}$ Saviani (1991; p. 21) observa que "o trabalho educativo é o ato de produzir, direta e intencionalmente, em cada indivíduo singular, a humanidade que é produzida histórica e coletivamente pelo conjunto dos homens. Assim, o objeto da educação diz

192

MATOS, Junot Cornélio. O trabalho pedagógico com a filosofia na escola. Griot : Revista de Filosofia, Amargosa - BA, v.21 n.3, p.189-196, outubro, 2021.
} 
Freire (1997). defendeu "o respeito à autonomia e à dignidade de cada um é um imperativo ético e não um favor que podemos ou não conceder aos outros". Como nós, os educandos são seres inconclusos e em formação. $\mathrm{O}$ que implica uma prática docente marcada pelo respeito recíproco, pois, reafirmamos, dentro da Comunidade Educativa, todos estamos, embora em níveis diferentes, envolvidos num processo formativo comum.

\section{A Filosofia na Escola}

Não é demais insistir que o professor de Filosofia na escola é, primeiramente, professor. Nesta, sua profissão está demarcada pelo ato de interagir com estudantes na sua formação pessoal e na construção de aprendizagens. É necessário entender que a educação, enquanto prática social realiza-se na instituição escolar atendendo a uma intencionalidade explicitada em sua dimensão institucional registrada no Projeto Político Pedagógico e planejada na mobilização coletiva de sua comunidade. Entretanto, como já refletimos, a instituição escolar não está "solta nos ares". Constitui-se em um tempo e espaço e observa objetivos educacionais que atendem à políticas e sua correspondente legislação que são forjadas na correlação de forças sociais e políticas que geram uma intencionalidade a partir de pactos, acordos e consensos de projetos em disputa. Com isso, atentamos para concepções de homem e mundo que prevalecem e são propostas hegemonicamente à escola. Mas nem por isso poderemos ceder ao discurso apressado da falência da escola ou de sua improdutividade. Nossa meta é a de caminharmos para a construção de uma Filosofia da Escola que a pense a partir de dentro e proponha-se em torno da fundamental questão: Que escola? Para quem?

Não ignoramos, conforme já informado, que a Filosofia, ao dirigir-se à Escola, recebe uma "encomenda" daqueles que visam a determiná-la de fora para dentro. Assim, pode ela, a filosofia, corroborar para a proposição de um modelo de homem/mulher e mundo preconizados por aqueles que, do seu exterior fora, tentam ditar qual é a formatação da escola que deverá corresponder ao projeto político vigente. Dessa forma, a Filosofia encomendada para a escola não é qualquer Filosofia. Não é aquela que paira na cabeça de filósofos militantes que podem concebê-la com espaço de formação de uma consciência construtora de mundos menos desiguais, ou aquela dos eruditos que a veem como uma possibilidade cultural para a frágil formação de nossa juventude, ou ainda aquela dos que a reduzem a um saber histórico. É imprescindível salientar que o trabalho do professor na escola define o seu compromisso para além da sala de aula, ou seja, com a proposta pedagógica da escola como um todo; ou melhor, com a sua própria reinvenção.

O que significa, então, levar a Filosofia à escola? A nosso ver, primeiramente, entendê-la como um trabalho da escola. Enquanto componente curricular será mediada pelas relações construídas nos processos de ensino e aprendizagem. Quer dizer, assume uma dimensão política no que respeita ao intrincado e quase sempre velado jogo de poder no interior da escola - e, outra, especificamente pedagógica.

É preciso esclarecer que a presença da Filosofia no currículo do Ensino Médio não representa 'salvação' da educação em geral ou uma espécie de 'redenção' da Educação Básica, como se coubesse à Filosofia, enquanto componente curricular, recuperar a qualidade do ensino, pois a responsabilidade pela construção de uma educação de qualidade diz respeito a todos que de algum modo estão envolvidos no processo educacional, e não a uma Disciplina em particular. Certamente, a Filosofia, pode contribuir significativamente nos processos do ensino e da

respeito, de um lado, à identificação dos elementos culturais que precisam ser assimilados pelos indivíduos da espécie humana para que estes se tornem humanos e, de outro lado e concomitantemente, à descoberta das formas mais adequadas para atingir esse objetivo".

MATOS, Junot Cornélio. O trabalho pedagógico com a filosofia na escola. Griot : Revista de Filosofia, Amargosa - BA, v.21 n.3, p.189-196, outubro, 2021. 
aprendizagem, no nível básico. Porém, não como um 'super-saber': algo acima ou superior às demais Disciplinas do currículo da escola básica; e nem o inverso: algo inferior, irrelevante, por isso, prescindível.

A presença da Filosofia nos processos de ensino e aprendizagem, pode ser entendida como relevante e pertinente, se for dada atenção para a contribuição potencial da Filosofia para que os educandos desenvolvam o pensamento criativo, reflexivo e intencional, com base numa concepção coerente do mundo (GRAMSCI, 1975). Para tanto, são insuficientes as Disciplinas tradicionais do currículo: Matemática, Física, Língua Portuguesa, História, Biologia etc.. Há a necessidade da concorrência, também, de outros saberes, dentre eles o saber filosófico. A diferença fundamental que há entre as outras Disciplinas do núcleo comum do currículo e a Filosofia, consiste na forma de abordagem do enfoque filosófico, que reside no tratamento específico, pontuado, global e radical, no sentido de ir às raízes da questão (SAVIANI, 1980: 17), que a Filosofia pode oferecer de diversos temas e assuntos que as outras áreas às vezes apenas o fazem de modo geral ou superficialmente.

O que significa para a Filosofia está na Escola? Alguns mais pragmáticos podem argumentar que com a obrigatoriedade de seu ensino abre-se um amplo mercado de trabalho para os egressos dos cursos de licenciatura em Filosofia. É verdade, mais além de insuficiente a resposta seria simplista. Parece que há um lugar importante para Filosofia, enquanto área do conhecimento, no sentido de integrar-se ao esforço de oferecer uma formação qualitativamente diferente para os adolescentes. Trata-se de interagir na construção de conhecimentos significativos e corroborar na finalidade da educação escolar de ser a base para a formação humana e profissional do estudante. Todavia, não basta, hoje, afirmar que é papel da Filosofia participar da formação da consciência crítica do estudante ou o desenvolvimento de seu raciocínio lógico. Como sabemos, outros componentes que integram o currículo também têm o intente de contribuírem em tal direção. Silva (1993: 802) reflete que

Diante da filosofia, a primeira pergunta que o professor naturalmente se faz é: qual filosofia? Se temos de convir com Schopenhauer que é desonesto ensinar uma filosofia como sendo a Filosofia, por outro lado o recorte que obrigatoriamente se opera na história e nas áreas temáticas não pode propiciar a perda do vigor da Filosofia como força interrogante, pois é isto que se trata principalmente de transmitir. Se não se pode deixar de assumir o lugar e onde se pensa e de onde se fala, é preciso também mostrar a inscrição deste lugar na pluralidade histórica, que afinal é o que lhe confere sentido. A dificuldade aumenta quando consideramos que a inserção não é apenas na história da filosofia mas na experiência individual, social e histórica do professor e dos alunos.

Kant, defendeu não ser possível ensinar filosofia, mas somente a filosofar (1984: 27). E entre o ensinar filosofia e o ensinar a filosofar, parece conter não somente a angústia que inquieta os educadores, mas a impossibilidade de resolver a dicotomia - se assim podemos dizer - que nos é apresentada. Isso se dá pela tradição cartesiana de precisar dividir cada parte com suas peculiaridades e justificativas, para se compreender o todo; ou por outro lado codificar, denominar algo como objeto e algo como sujeito para estabelecer o modo de relação existente e desta forma, compreender o processo na sua totalidade. A questão que nos permeia - ensinar filosofia ou filosofar - não se trata de um enigma, nem tão pouco de uma dicotomia (na qual há a necessidade de separações e antagonismos), mas observar esta questão como uma condição de tecissitura de cumplicidade: ensinando filosofia posso filosofar da mesma forma que filosofando, estou ensinando filosofia. Sendo assim, torna-se cada vez mais difícil elaborar uma fórmula pronta, uma didática única, uma metodologia modelo. A nosso ver, tais tentativas são uma espécie de assassinato do processo do filosofar, que embora possa ter um sistema e uma sistematização recordando a maiêutica como um exemplo - não podem existir como mero fruto de uma

MATOS, Junot Cornélio. O trabalho pedagógico com a filosofia na escola. Griot : Revista de Filosofia, Amargosa - BA, v.21 n.3, p.189-196, outubro, 2021. 
experiência científica ou como produto de um método, nem tão pouco ser reconhecido se for concebido a partir de um parâmetro instituído. Dessa forma, digamos que a filosofia precisa pensar mais a si mesma, que falar de si própria. E não somente ela, porém, todas as demais disciplinas, pois é fundamental seja no processo de formação como na prática docente, a construção de sentido, que a elaboração de itinerários pedagógicos onde na sua maioria se não forem compreendidos sendo somente obedecidos, não atingirão sequer o fim a que se propõem: a formação do indivíduo humano. Recordamos sobre o nascimento da pedagogia, Franco Cambi em sua obra História da Pedagogia no seguinte:

Com a Modernidade nasce a pedagogia como ciência: como saber da formação humana que tende a controlar racionalmente as complexas (e inúmeras) variáveis que ativam esse processo. Mas nasce também uma pedagogia social que se reconhece como parte orgânica do processo da sociedade em seu conjunto, na qual ela desempenha uma função insubstituível e cada vez mais central: formar o homem-cidadão e formar o produtor, chegando pouco a pouco, até o dirigente (CAMBI. 1999: 198).

Portanto, há um diálogo a ser construído no processo de ensino-aprendizagem na relação do filosofar que transcende a sensação de vivenciar uma aula em meio a tantas existentes simplesmente por uma questão conteudista. A filosofia não deve existir simplesmente para ser mais uma, nem tão pouco podemos acreditar e nos sentirmos confortáveis quando atingirmos a simpatia e empatia de todos os alunos que possuímos para importância e reconhecimento desta na escola como um dever cumprido. $O$ diálogo simplesmente está posto, as palavras a cada dia a conhecemos e aprendemos a utilizá-las, porém, as frases devem ser elaboradas e reelaboradas em cada existência, circunstância, realidade histórico-social e construída com e para os estudantes com todos os demais do processo.

MATOS, Junot Cornélio. O trabalho pedagógico com a filosofia na escola. Griot : Revista de Filosofia, Amargosa - BA, v.21 n.3, p.189-196, outubro, 2021. 


\section{Referências}

BADIOU, Alain. A situação da Filosofia no mundo contemporâneo. In. Para uma nova teoria do sujeito: conferências brasileiras. Rio de Janeiro: Relume-Dumará, 1994.

CAMBI, Franco. História da Pedagogia. São Paulo. Unesp, 1999.

COSTA, L. e RODRIGUES, L. Sala de Aula: o encontro nosso de cada dia. In: OSOWSKI, C. (Org.). Provocações da sala de aula. São Paulo: Loyola, 1999. Pp. 13-40

ENGUITA, Mariano. A Face oculta da escola: educação e trabalho no capitalismo. Tradução de Tomaz Tadeu da Silva. Porto Alegre. Artes Médicas, 1989.

FERREIRA JUNIOR, Wanderley J. Filosofia e Educação (Online), ISSN 1984-9605. Volume 3, Número 1, Abril de 2011- Setembro de 2011.

FREIRE, Paulo. Pedagogia da Autonomia - saberes necessários à prática educativa. Rio de Janeiro: Paz e Terra, 1997.

GRAMSCI, Antonio. Il Materialismo Storico. Torino. Ed. Reuniti, 1975.

KANT, E. Sobre a pedagogia. Tradução de Francisco C. Fontanella. Piracicaba: Unimep, 1999. MASSCHELEIN, Jan; SIMONS, Maarten. Em defesa da Escola. Uma questão pública. Tradução de Cristina Antunes. $2^{\text {a }}$ Ed. Belo Horizonte. Autêntica Editora. 2014.

MATOS, Junot Cornélio. Professor Reflexivo? Apontamentos para o debate. In GERALDI/FIORENTINI/PEREIRA, Corinta/Dario/Elisabete. Cartografias do Trabalho Docente - professor(a)-pesquisador(a). - Campinas/SP: Mercado de Letras - Associação de Leitura do Brasil (ALB). 1998 (Coleção Leituras no Brasil), 1998. Pp. 277 a 306.

MATOS, Junot Cornélio. Escola: Espaço para a formação de formadores. In: OSOWSKI, C. (Org.). Provocações de sala de aula. São Paulo: Loyola, 1999.

POSTIC, M. A relação pedagógica. Tradução de João Nunes Torrão. Coimbra: Coimbra Editora, 1984.

RABUSKE, E. Antropologia Filosófica. Porto Alegre: Escola Superior de Teologia São Lourenço de Brindes, 1981.

SILVA, M. Cecília P. da A Paixão de Formar: da psicanálise à educação. Porto Alegre: Artes Médicas, 1994.

SAVIANI, D. Educação: do Senso Comum à Consciência Filosófica. S. P.: Cortez. 1980.

SAVIANI, D. Pedagogia histórico-crítica: primeiras aproximações. São Paulo: Autores Associados, 1991.

SEVERINO, A. Joaquim. Filosofia da educação no Brasil: esboço de uma trajetória. In:GHIRALDELLI Jr. (Org.). O que é filosofia da educação? Rio de Janeiro: DP\&A., pp. 267328. 1999.

Autor(a) para correspondência / Corresponding author: Junot Cornélio Matos.junotcmatos@gmail.com 